\title{
The Growth Phases of Information Construction in Chinese Rural Area
}

\author{
Li-jun Wang \\ School of Environment and Resources, Beijing Normal University, Beijing 100875 \\ wljun1970@tom.com
}

\begin{abstract}
Information industry, which is regarded as the third technology wave in human history is irreversible trend in the world. The information construction in rural area is crucial factor in pushing forward rural economy, even for agriculture, rural economy, and farmer. To identify the growth phase of information construction in rural area is essential to assessment the process above. The paper analyzes the characteristics of each growth phases and market entities of information construction in rural area (the government, rural household, and market) which play role in the history of information construction in rural area, propose corresponding measures to safeguard sound development of information construction in rural area.
\end{abstract}

Keywords: information construction in rural area; investment entities; growth phase.

\section{Introduction}

Information industry, which is regarded as the third technology wave in human history is irreversible trend in the world. That is to say, the world has stepped into the information era. Information construction in rural area is the characteristics of modernization for social-economic development in countryside. From 2005 to 2008, the Central Document No. stressed the fourth consecutive year to promote information technology in rural areas, the Central Document No. 2009 is proposed "to encourage qualified local transformation of construction of rural multi-service centers", the use of information technology in building a more Good to promote peasant incomes. It is the key to solve agriculture, rural economy, and farmer. As a most populous developing country, the information construction in Chinese rural area must impact its social-economic development, even for the whole world.

Research on the field can promote the understanding the characteristics and trend of information construction in Chinese rural area. So far, a few researches have made progress in this field. Some researchers analyzed information construction in rural area present situation, proposed the countermeasures of further development (Wang et al., 2004, Zhang et., 2004). Others described the information infrastructure, service system, education system and so on in rural area (Zhao et., 2004). Additional researches paid 
attention to the relationship between "digital agriculture" and information construction in Chinese rural area, analyzed the probability and necessities of information construction in rural area in Shandong Province (Cao et., 2009).

These researches above focus on the regional information construction in rural area and present situation analysis. But few paper focus on the history of information construction in Chinese rural area. The paper attempted to identify the process above, analyzed its characteristics, the relationship between the information construction and social-economic development level, divide the phase of information construction in Chinese rural area at last.

\section{To Define the Entities of Information Construction in Chinese Rural Area}

The service target of information construction is rural area, and the service entity is rural household. Therefore, the rural household is the beneficiary and implementer, so the rural household involvement is the important indicator in the process of information construction in rural area.

The extent market intervene is considered to judge its role information construction in rural area. Along with the marketization development in rural area, market is more inseparable part in the process. Therefore, market is the primary entity and significant phase indictor of information construction in rural area.

Market economy development demonstrates: the all difficulties in economy don't overcome by market only. Given the fuller market positive role, government interference is essential, including industrial regulation, sector policy, financial subsidy and so on. The cooperation between market and government often guarantee the sound development of information construction in rural area.

In conclusion, rural household, market, and government are inseparable three parts, they are also the important indictors in dividing the phase of rural area information.

\section{Identification of Information Construction in Rural Area}

In accordance with the development, characteristics, interference of rural area information construction entities, this paper divide the history of $r$ information construction in rural area into three phases: (1) preliminary phase; (2) development phase; (3) mature phase.

\subsection{Preliminary Phase}

Like any other industry, information construction in Chinese rural area has also undergone the initial stage. Information construction in rural area consists of two parts: hardware and software. The hardware includes database, information pool platform, information dissemination media, and terminal equipments and so on; the software includes information processing, information management, and staff training, etc. 
Because of the amount of rural area is enormous, it is inevitable to invest a huge sum capital to finish information construction in rural area, under the circumstance, any enterprise and individual doesn't assume this task solely. In the light of public good theory, the majority equipments of information construction in rural area pertain to quasi-public goods. Therefore, the government acts on investment entity in the preliminary phase in information construction in rural area. Because of absence of credible information, rural household rides the fence toward information construction in rural area process (Fig 1).

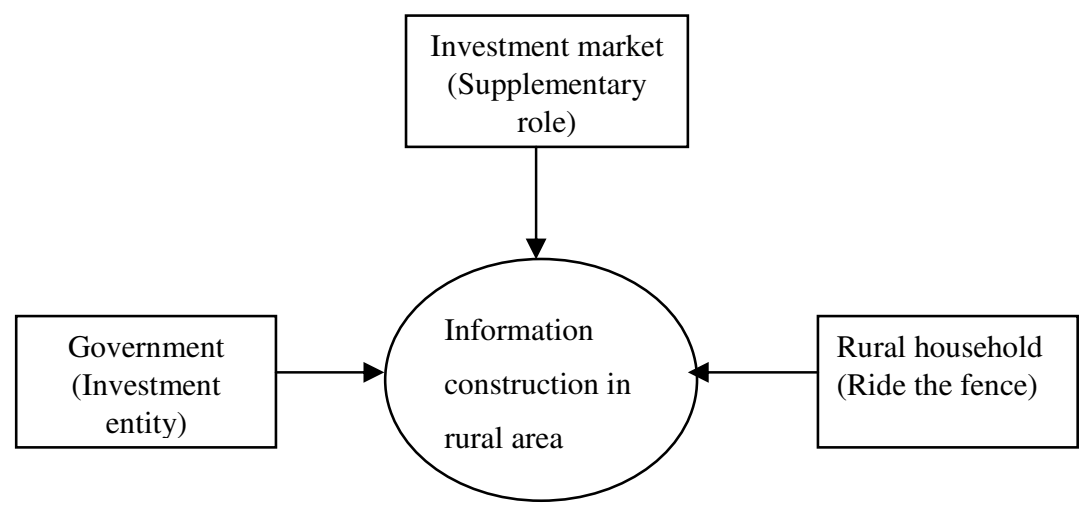

Fig. 1. Preliminary phase of information construction in Chinese rural area

\subsection{Development Phase}

In the preliminary phase, government invests enormous capital to build hardware infrastructure in preparation to step into development phase. In the process above, more and more rural household begin to be acquainted with the $r$ information construction in rural area, and benefit from it at the mean time.

On the basis of preliminary phase accumulation, the direction of information construction becomes cleaner than previous phase in the development stage. The commercial opportunities in information construction in rural area attract private capital to invest it. In this phase, the government continues to improve information construction in rural area infrastructure in a planned way, intensify the safeguard measures. For example, market accessible procedure, market operation for information construction in rural area, safeguard mechanism for rural household interest, etc. So market efficiency appeals to more capital, technology, and trained personnel to involve, accelerates information construction in rural area development, realizes the integration between market and area household. They actively participate in building to information construction in rural area to obtain more agriculture efficiency. At the moment, government, market, and rural household push forward information construction in rural area together, cooperation entity shifts from the cooperation among government, market, and rural household to diversified cooperation models (Fig 2). 


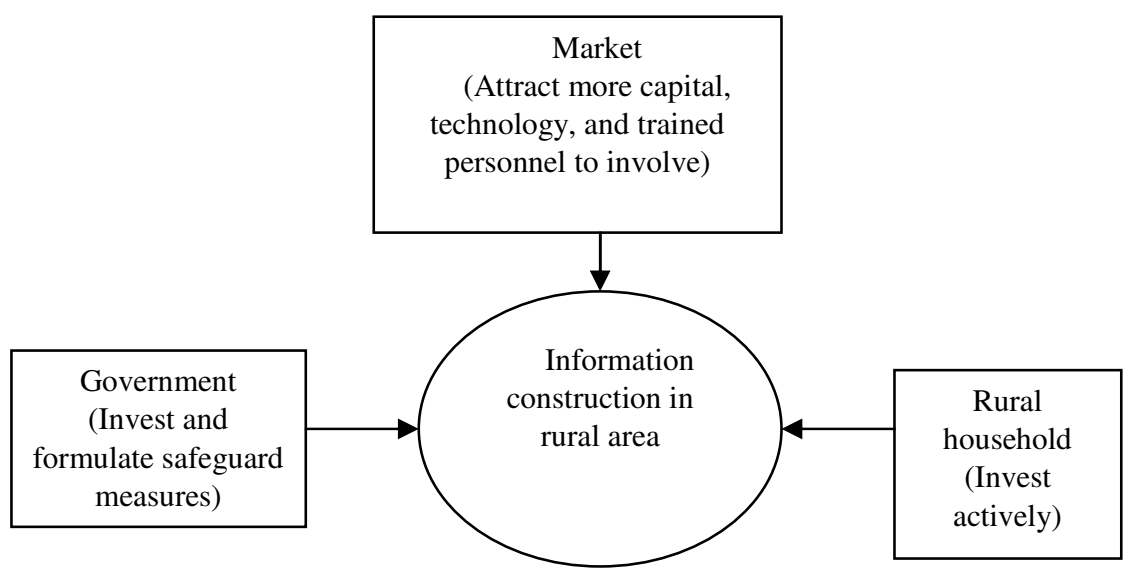

Fig. 2. Development phase of information construction in Chinese rural area

\subsection{Mature Phase of Information Construction in Rural Area}

During the development of information construction in rural area, all the entities cooperation become coordinated, diversified, steady, smoothly. All the interest of aspects tend towards maximum, it is the mature characteristics of information construction in rural area. In the course of this phase, rural area faces are remodeled completely, the farm's standards of living turn to better and better. At the moment, government withdraws from investment on hardware, put the emphasis on the necessary maintenance, strengthen safeguard measures for information construction in rural area, and recoup the investment in the previous two phases. Market and rural household play more important roles in information construction in rural area(Fig 3).

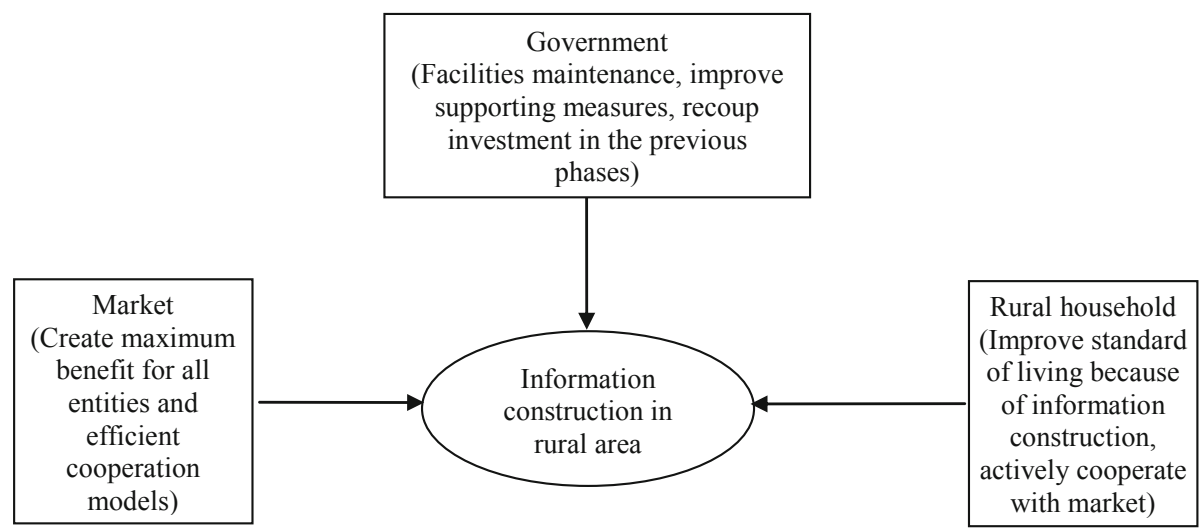

Fig. 3. Mature phase of information construction in Chinese rural area 
On the three phases of information construction in rural area above analysis, rural household is principal part in the process. The farmers' production and living are improved gradually, by the economic benefit driving, information construction in rural area can accelerate to development, which is essential instrument to solve agriculture, rural area, and farmer. Only under the government leadership, can the information construction in rural area develop steadily and soundly. Government plays invigorative, catalytic, and supportive role in the process.

\section{Development Countermeasures of Information Construction in Rural Area}

As far as the report from the Ministry of Agriculture of China (2009.7), all levels of agricultural sector have its own information construction department, possessing 200,000 stuffs. 31 provinces (autonomous regions and municipalities), $80 \%$ (city) and $60 \%$ of the county agricultural department have set up a special web site, initially forming a national agricultural information network group. Additionally, in accordance to the report from communications industry newspaper, 70 billion will be invested into information construction in rural area in the next 3 years, and strive to build 100,000 rural information service stations by 2011 , the agricultural information communication machine customers exceeds 100 million, information machines distributes all administrative villages, realize the goal of "one town one station, one village, one machine". We can infer from the above report, information construction in rural area still remains in its preliminary phase in the next few years. Market and rural household interference seldom occur. We should put the emphasis on the aspects below:

\subsection{To Propaganda Information Construction in Rural Area So that Farmer Understands and Accepts Its Importance}

Information construction in rural area turns towards rural area, combines farmer, services agriculture. Farmer plays utmost role in this process. In order to set up information construction in rural area, the government should establish links with farmer so that they understand the importance of information construction in rural area.

\subsection{To Push Forward Marketization of Rural Area Information}

Besides increase financial support, government ought to emphasize market intervene so that accelerate the step towards information construction in rural area. At present, the obstacles of market intervene originate from two aspects: (1) information asymmetry occurs between governmental policies and market players; (2) information asymmetry occurs between market players and policy makers.

\subsection{To Formulate Policy in Order to Safeguard Mechanism for Information Construction in Rural Area}

As the infant industry, information construction in rural area possesses expansive development space and speed. Meanwhile, indispensable policy is its safeguard. All 
level government should optimize information construction in rural area environment. For example: information sharing mechanisms, personnel training system, supervision and management mechanism.

\subsection{To Intensify Rural Area Information Management}

Unlike the traditional industrial management, information management possesses its own feature. Aiming at service agriculture, rural area, and farmer, information management should primarily disclose he relevant information of behaviors of principal part through different media instruments, and then inspire the principal part to improve their production and living behaviors. At present, we should set up agricultural database, support agricultural research, production, operation and management, technology generalization.

\section{Conclusion}

Information construction in rural area is at preliminary stage. All level government play role of investment. Therefore, we should vigorously explore information construction in rural area, attract private capital to intervene, combine farmer and other social sectors to participate, coordinate the benefit of investment entities, et up agricultural database, support agricultural research, production, operation and management, technology generalization and so on. In accordance with effective demand, heavy service, wide coverage, multi-mode requirements, integration of resources and build a platform to improve the rural information service system. Promote "McKinnon", "three-in-one" model of rural information and rural business information services, construction, information services and actively explore ways and means of villages and peasant households. Improve the collection and dissemination of agricultural information system for farmers and enterprises to provide timely and effective information services.

\section{Acknowledgments}

I am especially grateful to the reviewers to give many useful comments and advice. In the process of relevant study and paper writing, many workmate provide some beneficial helps. The responsibility for any errors rests solely with me.

\section{References}

Cao, H..X., Wang, J.L., Zhang, H.W.: Developing digital agriculture to promote rural information. Rural Area Information Network 1, 17-20 (2009)

Wang, H., Gao, Q.S., Li, L.Z.: Information construction in rural area in Zhangye City. Gansu Science and Technology 20(1), 14-16 (2004)

Zang, C.R., Chen, X., Liu, S.W.: Analysis of information construction in Chinese rural area. Journal of Human Agricultural University (Social Science) 5(4), 10-13 (2004) 
Zhao, W.Y., Yang, X.R., Zhao, Y.J.: Study on the information construction in Chinese rural area. Rural Area Information Network 2, 23-25 (2004)

[EB/OL] http: / / www.gov.cn/gzdt/2009-07/12/content-1363286.htm (24-7-2009)

[EB/OL] http: / /www. topoint. com.cn/ht-ml/article/2009/07/244522.html (24 -7-2009) 